\title{
Analysis on the Impacts of Sudden Stops of International Capital on the Volatility of Chinese Stock Market on the Basis of VAR Model
}

\author{
Junwei Xing ${ }^{1}$ \\ ${ }^{1}$ Research Institute of Provincial Conditions, Liaoning Provincial Party School of CPC, Shenyang, Liaoning \\ Province, China
}

Keywords: International Capital; Sudden Stop; Stock Market Volatility; Var Model.

\begin{abstract}
The financial crisis happened in emerging market countries in 1990s shows that, the sudden stops of international capital, which often lead to a series of chain reactions, is an important cause of financial crisis. In this paper, the sudden stops of international capital flows and the return ratio volatility of Shanghai Stock Market are chosen as research objects, in order to analyze the impacts of sudden stops on stock market. After building statistical models, it is found that the sudden stops of capital inflow have a positive impact on the volatility of stock market. That is, if the inflow of international capital suddenly stops, or relatively large quantity of outflow appears, positive fluctuations in stock market will happen. But the inverse relationship does not exist. The high volatility of stock market can not cause sudden stops of international capital flows. Finally, relevant suggestions are put forward according to the conclusions of this study.
\end{abstract}

\section{Introduction}

Since 1980s, with the development of financial system in western countries and the rapid capital accumulation, western capital began to flow into emerging economies. These emerging countries are in the period of rapid economic growth; international capital inflows can enjoy high return rates. At the same time, in order to accelerate the development pace, the emerging market countries also issued a series of preferential policies on international capital, foreign trade and foreign direct investment to attract capitals and promote industrial development as well as employment. On one hand, international capital flows really improve the economic situations of host countries. They not only promote the technological progress, but also boost the development of financial industry and economic internationalization. But on the other hand, they also bring huge potential risks to emerging economies. For instance, the financial crisis in Mexico, Asia and South America during 1994-2001 was caused by international capital flows. Normal international capital inflows in emerging market countries can be seen as "angel investment" which will bring a lot of benefits. But when the international capital inflows suddenly stop and begin to outflow, emerging countries will suffer from great negative impacts. But in recent years, the financial industry represented by capital market is becoming increasingly prominent in emerging markets. International capitals can also be seen as a kind of finance; their sudden stops will inevitably bring to rapid responses of the capital market which is represented by stock market. Capitals pursue profit. For “traditional capitals” , entering into the emerging market countries is a very good investment choice. But the capital markets in emerging market countries are newly developed; their supervision and operation systems are not perfect. The sensitivity of international capitals makes them speculative. The financial crisis happened in emerging market countries in 1990s showed that, the sudden stops of international capital inflows, which often led to a series of chain reactions, was an important cause of financial crisis. Therefore, this article mainly analyzes the influences of sudden stops of international capital flows on Chinese capital market (stock market), and puts forward to some corresponding suggestions to prevent capital market crisis. 


\section{The Determination of International Capital Flow Sudden Stops and Stock Market Volatility}

Measurement of international capital flow sudden stops (SS). Scholars use different calculation methods to define the sudden stops of capital. Calvo and his colleagues (2004) believes that, sudden stops of capital flows occur when compared with the previous year, capital inflows decrease by more than two standard deviations than the sample mean. Edwards (2005) believes that when sudden stops of capital flows occur, the net volume of capital inflows should decrease by more than $5 \%$ of GDP, and during the two years before the sudden stop, the country need to absorb more than 3/3 of local capital inflow. Cavallo and Frankel (2008) believes that the sudden stop of capital inflows means in that year, the surplus of financial account exceeds two standard deviations of the mean value. If the project decline in this year or next year, the per capita GDP should also decrease in that or next year. This paper argues that, the sudden stops of international capital happen on the basis of capital flows. So the volume of international capital inflow needs to be calculated first, then sudden stops can be calculated based on observation. For international capital flows, there are direct and indirect calculation methods. Through comparison, the author find that more deviations can be found in direct measurement of international capital flows and the method can be very inconsistent with the real situation. In 2001, China joined WTO. Since then, foreign direct investment and international trade in China have gradually expanded; hot money began to flow into and out of China in large volume. Thus, direct measurement can not accurately reflect the scale of international capital. The indirect method is an official statistical method approved by the National Bureau of Statistics of China. Generally speaking, it makes up for the deficiencies of the direct method, but it does not take the non monetary part in the actual use of FDI into account. Therefore, this paper finally decides to modify the indirect method; the final capital flow calculation formula is:

Short term capital flows = foreign exchange reserve assets increments - trade surplus -FDI+ short-term international capital hidden in the trade surplus + short-term international capital hidden in the FDI

For the short-term international capital hidden in the trade surplus and FDI, this paper refers to the method of regression model advocated by some scholars, and chooses progressive regression equation. For instance, the data of trade surplus and FDI volume from 2005 to 2008 is used to measure the amount of hidden short-term international capital in 2009. The specific steps go as follows. A regression model is established to predict Chinese trade surplus and the value of FDI; the true value (comes from official statistics) is used to minus the fitted value to get the scale of international capital inflows in China through trade and foreign direct investment.

In this paper, the original data of international capital flows comes from the database of National Bureau of Statistics and the website of Foreign Exchange Administration Bureau. The data period is from January 2006 to December 2013, and the results are shown in figure 1. It can be seen from figure 1, from 2006 to the first half of 2008, international capital pours into China. In the second half of 2008, the financial crisis broke, and there was a rapid outflow of international capital. But it was a short-term outflow; from 2010, capitals quickly returned to China (which may be related to the "four trillion" investment stimulus policy adopted by Chinese government at that time). From the beginning of 2011, net inflow and outflow occurred from time to time, and the market began to fluctuate more violently. 


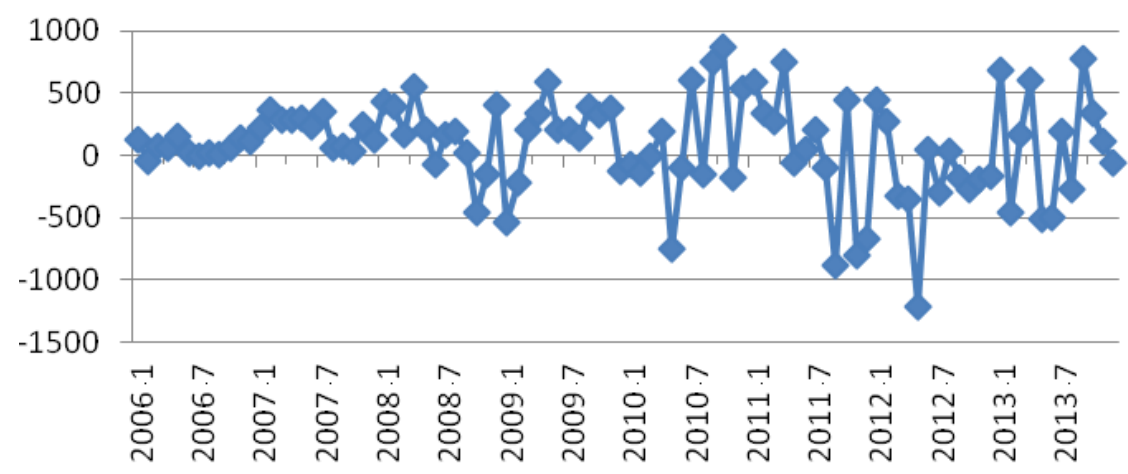

Figure 1 The scale of international capital flows in China during 2006-2013

When capital flows are available, indicators can be designed to measure the sudden stops of capital flows. Theoretically, sudden stops means the net inflows of capital cannot continue; net inflows may decrease rapidly, or net outflows appear. Some scholars use dummy variables; if the capital outflow occurs, the value is defined as 1 ; otherwise the value is defined as 0 . Rothenberg and Warnock (2006) define the sudden stop as:

$$
\begin{aligned}
& \Delta C F_{t}=C F_{t}-C F_{t-1} \\
& \Delta C F_{t}<\mu\left(\Delta C F_{t}\right)-\sigma\left(\Delta C F_{t}\right)
\end{aligned}
$$

Among them (1) is the change of international capital; if form (2) is satisfied, sudden stop begins.

This article takes into account of monthly data, and uses dummy variables to represent the sudden stops of capital flow more intuitively. Among them, the data of monthly changes in international capital flows is calculated firstly. If the amount of change is less than -50 billion, which means compared with the previous month, the outflow of this month exceeds $\$ 5$ billion, the value is defined as 1 (represent the sudden stop of capital inflows); otherwise the value is defined as 0 .

Estimation and description of Chinese stock market volatility. There are two kinds of measure method to evaluate the volatility of stock market: non conditional volatility and conditional volatility. Non conditional volatility is mainly based on standard deviation or variance, and conditional volatility is mainly based on GARCH model. This paper uses GARCH model. Considering that the domestic investors prefer to use the Shanghai Composite Index to determine the trend of Chinese stock market, this paper chooses monthly Shanghai stock indexes from the same period as research object. Data comes from the software of Straight Flush.

Using the ARMA $(2,2)$-GARCH $(1,1)$ model, the conditional standard deviations of the Shanghai composite index return series are estimated as the volatility indictors of return series, and the results are shown in figure 2. As it can be seen in Figure 2, the volatility rates of Shanghai Composite Index are greatest in 2007-2009, and lowest in the last three years.

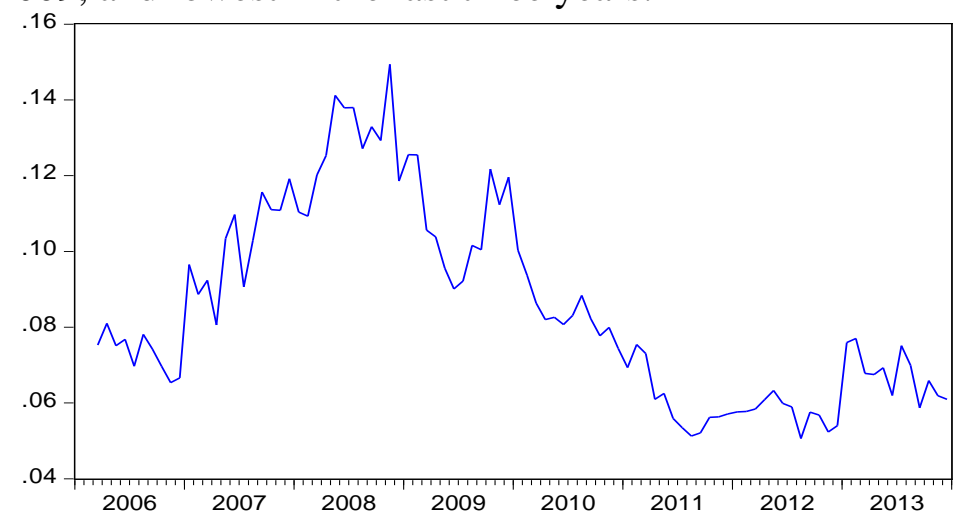

Figure 2 Volatility of Shanghai composite index return series 


\section{Empirical Analysis on the Impacts of International Capital Sudden Stops on Stock Market Volatility}

First of all, the roots of unity of two variables are analyzed through stationary test, and the results are shown in table 1.

Table 1. Stationary test for roots of unity of each variable

\begin{tabular}{lllll}
\hline variable & ADF statistics & Test type & 5\% critical value & Prob \\
\hline SS & -12.3088 & $(1,1,0)$ & -3.4578 & 0.0000 \\
\hline vol & -4.5119 & $(1,1,1)$ & -3.4588 & 0.0120 \\
\hline
\end{tabular}

Note: in the test type (c, t, q), c, t, and q represent constant items, time trends and lag orders respectively

As it can be seen in Table 2, the ADF test statistic value of the original sequence variable SS is -12.3088; corresponding significant probability level is $\operatorname{Prob}<5 \%$, indicating that the capital flow suddenly stops and the variable sequence is stable. For the conditional volatility series of Shanghai Composite Index yield, vol, the ADF test statistic value is -4.5119 , and the significant probability level Prob $<5 \%$, indicating that the sequence is also stable. Therefore, the vector autoregressive model and the Granger causality test can be established.

Before setting up VAR model, the number of lag periods should be judged firstly. The AIC and SC criteria are generally used to decide which lag order is the smallest and should be selected to establish the model. This paper compares starts models which are built from the first period to the fourth period of lag. After comparing, when lag is 1, AIC and SC are minimum; so the lag order is 1 . The VAR (1) model estimates the equation as follows:

$$
\begin{aligned}
S S_{t}= & 0.439-0.206 S S_{t-1}+1.200 \mathrm{vol}_{t-1} & R^{2}=0.642 \\
& (2.42)(-1.969) \quad(0.589) & \\
\text { vol }_{t}= & 0.007+0.007 S S_{t-1}+0.958 \mathrm{vol}_{t-1} & R^{2}=0.893 \\
& (2.160)(4.187) \quad(27.370) &
\end{aligned}
$$

The estimation results of equation show that, among the dependent variables, the variable coefficient of SS lag 1 is significant at the probability level of $5 \%$, but the coefficient is negative $(-0.206)$, indicating that the sudden stop of international capital in the previous period will weaken the outflow of international capital in the next period. For the Shanghai composite index yield volatility, vol, the lag 1 coefficient is not statistically significant at the probability level of $5 \%$, indicating that the volatility of Shanghai stock index return can not affect the outflows of international capital.

For the dependent variable vol, SS lag 1 variable coefficient is statistically significant at the probability level of $5 \%$, the coefficient is positive (0.007), indicating that the sudden stop of capital flow on the previous period has a significant positive impact on stock market volatility at that period. The coefficient of vol in the next lag period is also positive at the probability level of $5 \%$, and the coefficient is 0.958 . This shows that continuity exists in stock market volatility, which also manifests the volatility clustering feature of the stock market.

On the basis of VAR model, the impulse response function can be used to estimate the shock response between variables; the results are shown in figure 3. Figure 3 represents the impulse response function of SS (itself) caused by the impact of SS in the upper left corner. It can be seen that when SS receives positive impact of a standard deviation, it responses positively in the first period; but the response rapidly decline in the second period, and in the third period the response value is almost zero. In the upper right corner, there is the pulse response diagram of SS caused by the impact of vol. It can be seen that when SS receives a positive shock of standard deviation in this period, the 
response is almost zero from the first to tenth periods after the shock. The lower left corner of Figure 3 is the pulse response diagram of vol caused by the impact of SS. It can be seen that when vol receives positive shock of a standard deviation in this period, its response in the first period is negative; but the response turns to be positive from the second period and remains weak positive to the tenth period. The lower right corner of Figure 3 is the pulse response function diagram of vol (itself) caused by the impact of vol. It can be seen that when a positive deviation of vol is given in this period, there will be a strong positive response in the first period after the shock; then the response weakens, but remains positive.

Response to Cholesky One S.D. Innovations ?2 S.E.

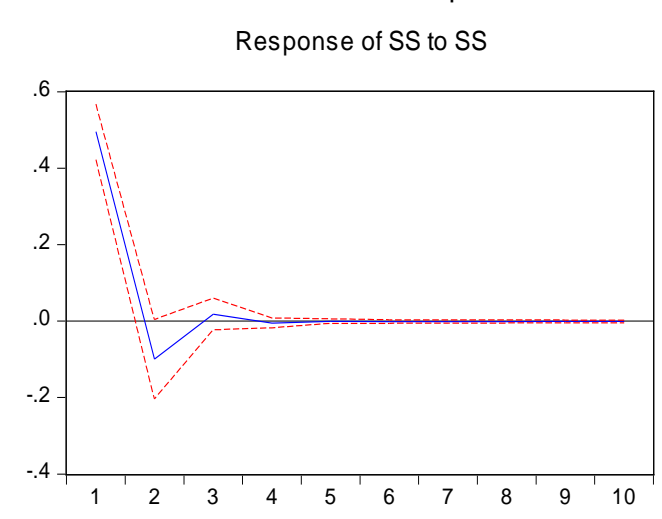

Response of SS to VOL

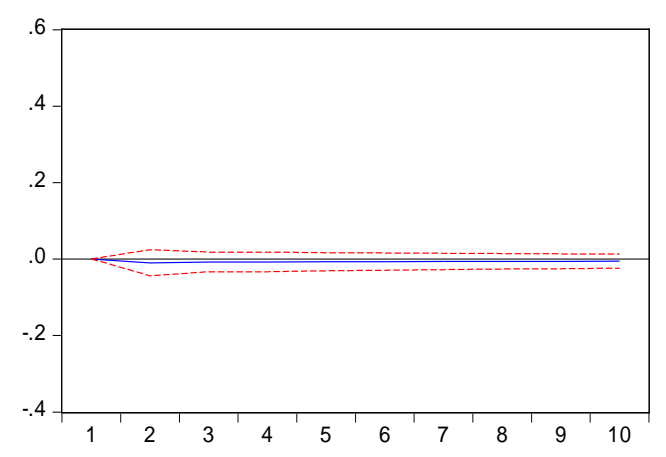

Response of VOL to SS
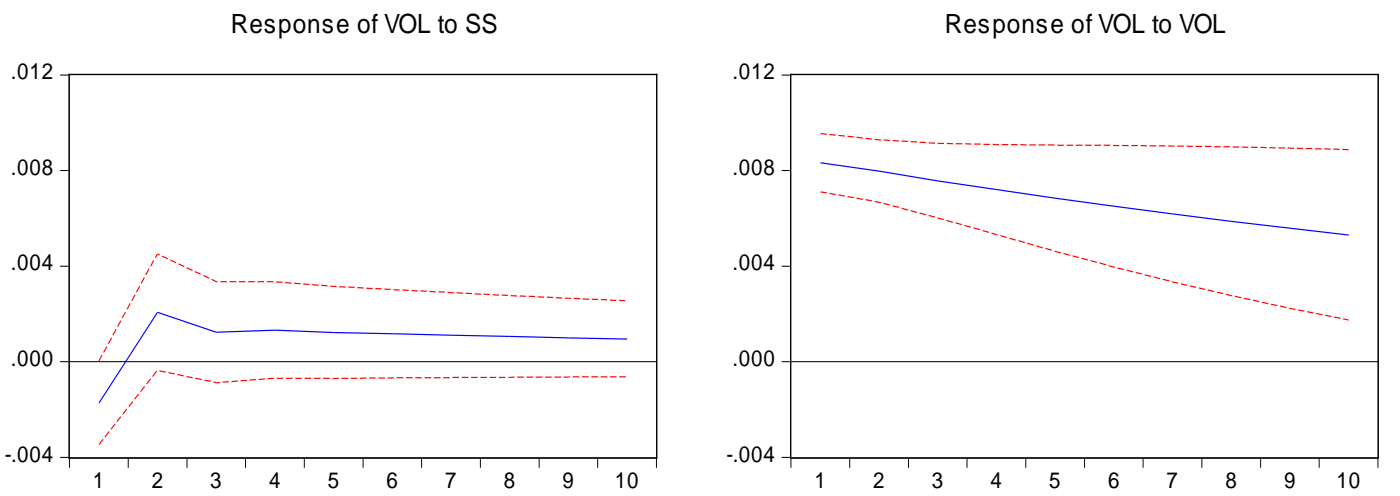

Figure 3 Impulse response diagram of capital sudden stop and stock market fluctuation

To further analyze the causal relationship between the sudden stops of capital flows and the volatility of stock market, the Granger causality test is used. For the lag phase, the 1st to 4th lag periods are chosen. The results can be found in table 2. In the 1st lag period, for the null hypothesis that SS is not the Grainger reason of vol, the $\mathrm{F}$ statistic value corresponding probability level Prob $=0.000$. The null hypothesis is rejected, indicating that the sudden stop of capital is the Grainger reason of stock market volatility. For the original hypothesis that vol is not the Grainger reason of SS, the corresponding probability level of F statistic value is Prob=0.5575. The null hypothesis is not rejected, so the stock market volatility, vol, is not the Grainger reason of capital sudden stops, SS. When the 2nd, 3rd and 4th lag period are chosen, same results can be obtained. Therefore, the Granger causality test shows that the sudden stops of international capital inflow will lead to the fluctuation of Chinese stock market, while the fluctuation of Chinese stock market will not cause the sudden stop of international capital inflow. 
Table 2 Grainger causality test

\begin{tabular}{c|c|c|c}
\hline Lag & Null Hypothesis: & F-Statistic & Prob. \\
\hline \multirow{2}{*}{1} & SS does not Granger Cause VOL & 17.5299 & 0.0000 \\
\cline { 2 - 4 } & VOL does not Granger Cause SS & 0.34667 & 0.5575 \\
\hline \multirow{2}{*}{2} & SS does not Granger Cause VOL & 6.66485 & 0.0020 \\
\cline { 2 - 4 } & VOL does not Granger Cause SS & 0.57229 & 0.5663 \\
\hline \multirow{2}{*}{3} & SS does not Granger Cause VOL & 5.30373 & 0.0021 \\
\cline { 2 - 4 } & VOL does not Granger Cause SS & 0.60721 & 0.6121 \\
\hline \multirow{2}{*}{4} & SS does not Granger Cause VOL & 3.97026 & 0.0054 \\
\cline { 2 - 4 } & VOL does not Granger Cause SS & 0.42337 & 0.7913 \\
\hline
\end{tabular}

\section{Conclusions and Suggestions}

Normal international capital inflows in emerging market countries can bring a lot of benefits. But when the international capital inflows suddenly stop and huge amount of capitals begin to outflow, negative impacts will happen to emerging countries. This paper mainly investigates the impacts of sudden stops of international capital flows on the volatility of Chinese stock market; it defines the calculation rules of international capital flow sudden stops and describes the fluctuation of stock market. By analyzing monthly data from 2006 to 2013, the statistical empirical results show that the sudden stops of Chinese capital inflow have a positive impact on the volatility of stock market. That is, if the inflow of international capital suddenly stops, or relatively large quantity of capital outflows, positive fluctuations in the stock market will happen. But the inverse relationship does not exist. The high volatility of stock market cannot lead to sudden stops of international capital flows.

Through the conclusions of empirical research, this paper puts forward to following suggestions.

Strengthen the supervision of invisible capital in international capital flows, so as to prevent the rapidly flowing of hot money. After more than ten years' accumulation, the scale of international capitals in China is huge. The investment methods and directions of these capitals change unpredictably, which does not only pose a threat to the capital market of emerging market countries, but also brings potential risks to emerging economies. Therefore, relevant state departments should intensify the supervision of hidden international capital flows in foreign direct investment and international trade, and intensify the control of international capital through the supervision of illegal private bank and other covered ways. The authorities do not only need to prevent the sudden outflows of international capitals, but also need to block international capital inflows in large amounts.

Introduce investigation system for funds entering stock market and capital market, so as to prevent the international capital from disturbing the capital market order of our country. The capital market is of great importance to the economy and finance of a country. One of the principles of developing capital market is to maintain the healthy and stability development, and to avoid high volatility and high leverage. While the speculation of international capital makes it easy to obtain large profits in the stock market and futures market, which can cause radically changes in stock and futures markets. It is not conducive to the healthy development of domestic investment industry. Therefore, we should control large sums of funds and large transactions in the capital market; in particular, we need to prevent international investment funds from shorting Chinese stock market. 


\section{References}

[1] K.F. Zhang, Study on factors affecting the sudden stops of capital flow in emerging economies, J. China’ s Prices. 1(2016): 51-54.

[2] J. Han, J.M. Chen, A. Li, Will the surge in capital inflows cause sudden disruptions? An empirical study based on emerging market countries, J. Journal of Financial Research. 3 (2015): 36-50

[3] X.Y. Fan, S.S. Pan, B. Wang, Economic and social influences of sudden stops of international capital flow, J. Economic Perspectives. 5 (2011): 118-123.

[4] X. Zheng, The formation mechanism and enlightenment of sudden stops of international capital flow in emerging market countries, J. Finance and Economy. 10 (2015): 20-25.

[5] Y. Z. Guan, L.Y. Liu, T.X. Cheng, Study on the early-warning index system for sudden stops of international capital flows, J. Journal of Finance and Economics. 2 (2013): 4-15.

[6] N.Y. Li, The impacts of sudden stops of capital inflows on Chinese economy-- analysis based on VAR model. Shandong University, 2011.

[7] Y. Rao, New classification of sudden stops of international capital flows and its impacts on output. Capital University of Economics and Business, 2015.

[8] L.H. Wu, G.M. Fu, Interactions between RMB exchange rates, short-term capitals and stock prices, J. Economic Research Journal. 11(2014): 72-86.

[9] Y.B. Zhang, Empirical analysis on the relationship between short-term international capital flows and Chinese stock market, J. Modern Business Trade Industry. 2 (2013): 112-113.

[10] D. Jin, International short term capital flows and Chinese stock market volatility-analysis based on co-integration, J. Times Finance. 11 (2013):47-50 